\title{
Epidemiology of Cigarette and Smokeless Tobacco Use among South Asian Immigrants in the Northeastern United States
}

\author{
Cristine D. Delnevo, ${ }^{1}$ Michael B. Steinberg, ${ }^{2}$ Shawna V. Hudson, ${ }^{3}$ \\ Rajiv Ulpe, ${ }^{4}$ and Robert S. DiPaola ${ }^{5}$ \\ ${ }^{1}$ UMDNJ-School of Public Health and The Cancer Institute of New Jersey, 335 George Street, Suite 2100, New Brunswick, \\ NJ 08903, USA \\ ${ }^{2}$ UMDNJ-Robert Wood Johnson Medical School and The Cancer Institute of New Jersey, 125 Paterson Street, Room 2300, \\ New Brunswick, NJ 08903, USA \\ ${ }^{3}$ UMDNJ-Robert Wood Johnson Medical School and The Cancer Institute of New Jersey, 195 Little Albany Street, Room 5569, \\ New Brunswick, NJ 08903-2681, USA \\ ${ }^{4}$ UMDNJ-School of Public Health, 335 George Street, Suite 2100, New Brunswick, NJ 08903, USA \\ ${ }^{5}$ UMDNJ-Robert Wood Johnson Medical School and The Cancer Institute of New Jersey, 195 Little Albany Street, Room 2002B, \\ New Brunswick, NJ 08903-2681, USA
}

Correspondence should be addressed to Cristine D. Delnevo, delnevo@umdnj.edu

Received 31 December 2010; Accepted 2 March 2011

Academic Editor: Aditi Chatterjee

Copyright (C) 2011 Cristine D. Delnevo et al. This is an open access article distributed under the Creative Commons Attribution License, which permits unrestricted use, distribution, and reproduction in any medium, provided the original work is properly cited.

\begin{abstract}
As the most preventable cause of death in the world today, understanding tobacco use among one of the fastest growing ethnic/ racial groups is warranted. We explore cigarette and smokeless tobacco (SLT) use among South Asians in NJ and the Northeast using the Tobacco Use Supplement to the Current Population Survey. Overall, tobacco use rates among South Asians were similar or lower than the population. However, in NJ, South Asian males had the highest SLT rate $(2.7 \%)$ and in the Northeast, White $(\mathrm{AOR}=5.8,95 \% \mathrm{CI}=3.7-9.4)$ and South Asian males $(\mathrm{AOR}=4.0,95 \% \mathrm{CI}=1.5-10.6)$ had significantly higher odds of current SLT use relative to non-White males. Tobacco use among South Asians was not homogeneous; Pakistanis are overrepresented among cigarette smokers while Indians are overrepresented among SLT users. Given the differential tobacco use among and within South Asian, disaggregating data to understand tobacco use behaviors is necessary to develop effective interventions for tobacco cessation.
\end{abstract}

\section{Introduction}

Tobacco is the single most preventable cause of death in the world today, including South Asian countries like India where there are disparities in chronic diseases like cancer and cardiovascular disease that have surpassed infectious disease as the leading causes of death. South Asians are the third largest Asian group in the United States, comprising 1.89 million people and are among the fastest growing racial groups in New Jersey and the Northeast [1]. In 2000, one out of three South Asians reside in the Northeast, and there were almost 170,000 South Asians living in New Jersey, representing the 3rd largest statewide South Asian population in the country with the large majority of South Asian immigrants coming from India, Pakistan, Bangladesh, and Sri Lanka [1].

Despite marked health disparities in South Asians internationally compared to the US population (e.g., cancer, heart disease, and diabetes) [2-4], little is known about the health status of South Asians residing in the US Paradoxically, the South Asian population in the US is generally viewed as a successful immigrant group, resulting in a characterization known as the "Model Minority Myth." This concept describes a minority ethnic, racial, or religious group whose members achieve a higher degree of success, affluence, and thus good health, than the population as a whole. However, 
recent data strongly contradict the notion that South Asians are uniformly affluent and healthy and highlight the growing heterogeneity of this group $[1,2,5,6]$.

Indeed, India is the second largest consumer of tobacco in the world, and national data indicate that $47 \%$ of men and $14 \%$ of women either smoke or chew tobacco [7]. Likewise, nearly one out of three adults in Bangladesh use some form of tobacco [8], and one out of three Pakistani males use tobacco daily [9]. Studies conducted in the UK suggest that South Asians who immigrate may have lower rates of smoking overall than the general population $[10,11]$. However, other studies have found high rates of smoking in certain subgroups of South Asians, particularly Bangladeshis $[12,13]$. Studies of tobacco use in South Asian immigrants in the US are limited and not applicable to the general population for two main reasons. First, studies have been geographically limited to a community, city, or single state [14-17]. Second, despite the traditional role of smokeless tobacco in South Asian cultures, some studies have focused only on cigarette smoking $[2,16,17]$.

The paucity of research on tobacco use behaviors in South Asians is due in part to the fact that despite a distinct cultural and geographical background, South Asians are almost always aggregated into a broad "Asian" category, thus potentially masking subgroup differences and preventing identification of potential health disparities between subgroups. However, given that the explosive growth in the South Asian population is fairly recent and largely attributed to immigration, it is methodologically possible to identify South Asians in the Tobacco Use Supplement to the Current Population Survey (CPS), as the survey collects country of origin. The current study is the first to use population level behavioral surveillance data to explore patterns of cigarette and smokeless tobacco use among South Asians residing in New Jersey and the Northeast US and to explore tobacco use behavior by country of origin.

\section{Methods}

2.1. Data Source. We analyzed New Jersey and Northeast specific data from the 2003 and the 2006/7 Tobacco Use Supplement to the Current Population Survey (TUS-CPS). The details of the TUS-CPS sampling design and data collection methods are provided elsewhere [18]. In brief, the TUS-CPS uses an area probability sampling design to select a stratified probability sample of clusters of households. Approximately 56,000 households are surveyed in a given month using computer-assisted telephone interviewing (CATI) and computer-assisted personal interviewing (CAPI) methods. State estimates may be generated from the national TUS by combining multiple months of data. Individual level self-response rates for the TUS-CPS questionnaire are approximately $65-72 \%$ for those households completing the basic CPS household survey (response rates range from 93 to $97 \%$ ). To increase sample size, we merged data from 2003 and 2006/7 for our analyses. The overall sample size for New Jersey was 7,354, of which 176 were South Asian, and for the Northeast there were 71,152 total cases of which 583 were South Asian.
2.2. Race/Ethnicity, Country of Origin, and Immigrant Status Measures. We constructed a single, five-level variable for race/ethnicity which included White, Black, Hispanic, Asian, and South Asian. This was constructed from five survey questions: race, Hispanic origin, country of origin, mother's country of origin, and father's country of origin. South Asians were defined as those individuals who indicated that their country of origin or the country of origin for one of their parents were from India, Pakistan, or Bangladesh. While the TUS did not permit the identification of other South Asian countries of origin (e.g., Sri Lanka, Nepal), the three countries we could identify comprise $98.5 \%$ of South Asian immigrants in the US [1]. In addition, we created an additional variable for South Asians only that reflected their immigration status and country of origin which resulted in four mutually exclusive categories: first generation American of South Asian descent (i.e., born in the US, but at least one parent is from India, Pakistan, or Bangladesh), immigrant from India, immigrant from Pakistan, and immigrant from Bangladesh.

2.3. Tobacco Measures. We applied standard tobacco surveillance criteria for calculating adult tobacco use prevalence [19]. Our measures of cigarette smoking were derived from three questions resulting in two measures: ever smoker (i.e., smoked 100 cigarettes in their lifetime), and current smoker (i.e., smoked 100 cigarettes and now smokes everyday or some days). With respect to smokeless tobacco, the TUSCPS does not include a lifetime threshold question (e.g., smoked 100 cigarettes) for smokeless tobacco use, but does inquire about snuff tobacco and chew tobacco separately. Our measures of smokeless tobacco use were derived from four questions resulting in two measures: ever smokeless user (i.e., has used snuff or chew), and current smokeless user (i.e., now uses snuff or chew everyday or some days).

2.4. Analysis. Sample replicate weights were applied to adjust for nonresponse and the varying probabilities of selection, including those resulting from oversampling, providing results representative of New Jersey and the Northeast's adult population. SUDAAN statistical software, which corrects for the complex sample design, was utilized to generate point estimates and adjusted odds ratios (AOR) with 95\% confidence intervals [20].

\section{Results}

Overall, $74.8 \%$ of adults in the Northeast were White, 10.5\% were Black, 9.7\% were Hispanic, 3.6\% were Asian/PI (not South Asian descent), and 1.3\% were South Asian. As shown in Table 1, South Asians are demographically different than their White, Black, Hispanic, and Asian counterparts. First, South Asians were more likely to be male $(60.0 \%)$ compared to all other racial/ethnic groups and to the overall sample $(47.5 \%)$. With respect to age, South Asians had a lower proportion of adults over the age of 65 compared to Whites, Blacks, and Asians. South Asians also had the largest proportion of adults with at least a college 


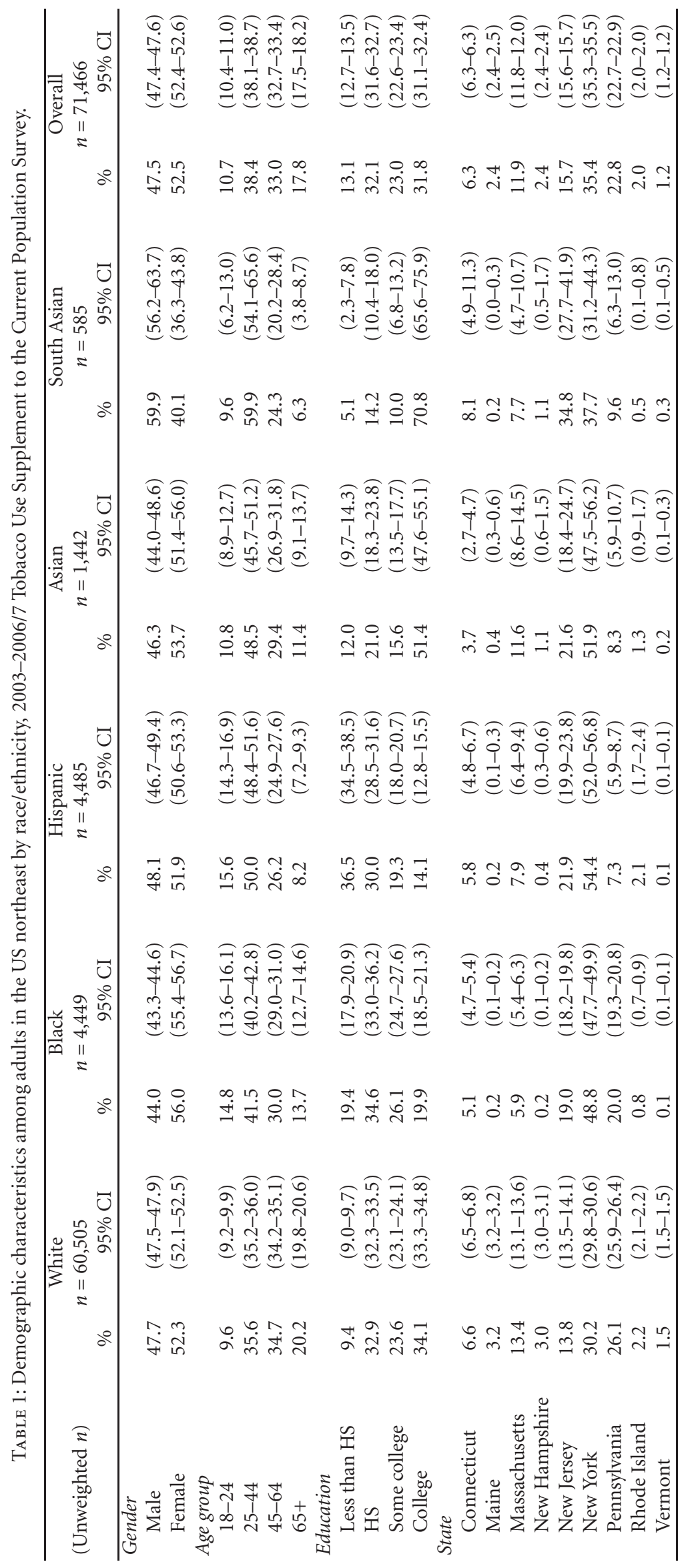


education $(70.8 \%)$; this is more than twice the rate of Whites overall, and three to four times the rate of Black and Hispanic adults. Lastly, within the Northeast, South Asians are overrepresented in New Jersey with $34.8 \%$ residing there.

Table 2 summarizes the prevalence of current and ever cigarette and smokeless tobacco use in New Jersey and in the US Northeast by race/ethnicity and gender. Overall, 16.9\% of males in New Jersey report currently smoking cigarettes and South Asians had current smoking rates (12.0\%) below their other racial/ethnic counterparts. This pattern is consistent in the Northeast. In general, South Asian females had low rates of cigarette smoking both in New Jersey and the Northeast.

Smokeless tobacco use is predominately a white male behavior in the US, yet in NJ, South Asian males $(2.7 \%$ ) have the highest rates of current use among males. In the northeast, South Asian males (1.4\%) currently use smokeless tobacco at a rate somewhat lower, but not significantly different from White males $(2.3 \%)$. These rates are somewhat confounded by the different ages and educational status of South Asians, as smokeless tobacco use is more common among younger adults and those with lower levels of education. When education and age are adjusted for in a logistic regression, white males $(\mathrm{AOR}=5.8,95 \% \mathrm{CI}=3.7-$ 9.4) and South Asian males $(\mathrm{AOR}=4.0,95 \% \mathrm{CI}=1.5-10.6)$ had significantly higher odds of current smokeless tobacco use relative to non-White males. Rates of smokeless use are extremely low among females of all racial/ethnic groups both in New Jersey and the Northeast. However, ever smokeless use is notable among South Asian females in New Jersey $(1.7 \%)$ compared to females overall in New Jersey $(0.2 \%)$.

Tobacco use behavior among South Asians is not homogeneous (see Table 3). Overall, in the Northeast, while Pakistanis make up only $9.6 \%$ of all South Asian males, they are overrepresented among current cigarette smokers, but not ever smokers, raising questions about cessation. Indeed, the ever smoking rate among Pakistani males in the northeast is $24.3 \%$, and the current smoking rate is $22.4 \%$, suggesting that few male Pakistani ever smokers have quit. On the other hand, Indian males who make up $70 \%$ of all South Asians, comprise $85.9 \%$ of the current smokeless tobacco users. Lastly, the data suggest a possible acculturation effect among females. Indeed, while first generation female Americans of South Asian descent comprise $17.6 \%$ of South Asian females overall, they are overrepresented among South Asian female cigarette smokers $(50.0 \%)$.

\section{Discussion}

This study represents one of the only descriptions of tobacco use by South Asians in the United States at the population level. Despite common misperceptions regarding health behaviors and status, South Asians in this study demonstrate important tobacco-use behaviors including lower quit rates, high rates of smokeless tobacco use, and significant heterogeneity regarding these behaviors. Our data support the existing literature demonstrating lower rates of cigarette use in South Asians than other racial/ethnic groups [10, 11]. Similar to the prior data by Choi et al. [21], our study supports the hypothesis that acculturation has a beneficial effect in Asian American men and harmful effects on women and adolescents.

Despite having lower rates of ever and current cigarette smoking than other racial/ethnic groups, it is important to recognize cigarette smoking behavior differed by country of origin among South Asian males, and the data suggest that Pakistani males who have ever smoked cigarettes continue to use tobacco. This may be partially explained by the age distribution of South Asians, who tended to be younger; a group that is less likely to quit than older ever smokers. However, the findings do raise concern that South Asian immigrants who smoke may be less motivated to quit and/or have a more difficult time stopping smoking. This possibility is supported in the, albeit limited, research literature. In the UK, the intention of South Asian males to give up smoking was similar to the general population; however, actual quit rates were much lower, and utilization of cessation services was lower among South Asians [13]. Reasons for this are unclear. Bush et al. [12] suggested that the social acceptability of smoking in Pakistani and Bangladeshi communities may contribute to a lower quit rate while White et al. [22] noted a low level of awareness of the health risks associated with smoking and insufficient use of professional advice/smoking cessation aids among this population.

Smokeless tobacco use is an especially important behavior among certain South Asians, especially males and those from India. While in the US, smokeless tobacco refers to moist snuff or chewing tobacco, the term "smokeless tobacco" is broad and refers to over 30 different types of products including those indigenous smokeless tobacco products that are most frequently used in South Asia, including but not limited to paan, paan masala, zarda, betel quid with tobacco, and gutka [23-25]. Health effects linked to smokeless tobacco use in general include oral cancer, pancreatic cancer, oral diseases such as periodontal diseases, precancerous lesions, and risk factors for cardiovascular diseases, diabetes, reproductive health effects, and overall mortality [25]. Moreover, there is conclusive evidence that betel quid chewed with and without tobacco, tobacco with lime, and other tobacco mixtures specific to South Asian smokeless tobacco products increase the risk of oral cancer [24]. Not surprisingly, data indicated that oral cancer incidence and mortality among people of South Asian descent are almost twice those of global rates [26] and are largely attributed to the use of indigenous tobacco products [27]. Data from the UK, Canada, and California suggest that South Asian immigrants may maintain these higher rates of oral cancer compared to general population [28-31]. Given the growth in this population, future cancer surveillance is clearly warranted.

Finally, the heterogeneity of this sample of South Asians demonstrates that generalization of tobacco surveillance findings can lead to erroneous conclusions. For example, this group of South Asians illustrates high rates of cigarette smoking among Pakistanis while Indians represent most smokeless tobacco users. While studies conducted in the UK and the US have suggested that South Asians in aggregate may have lower rates of smoking than the general population 


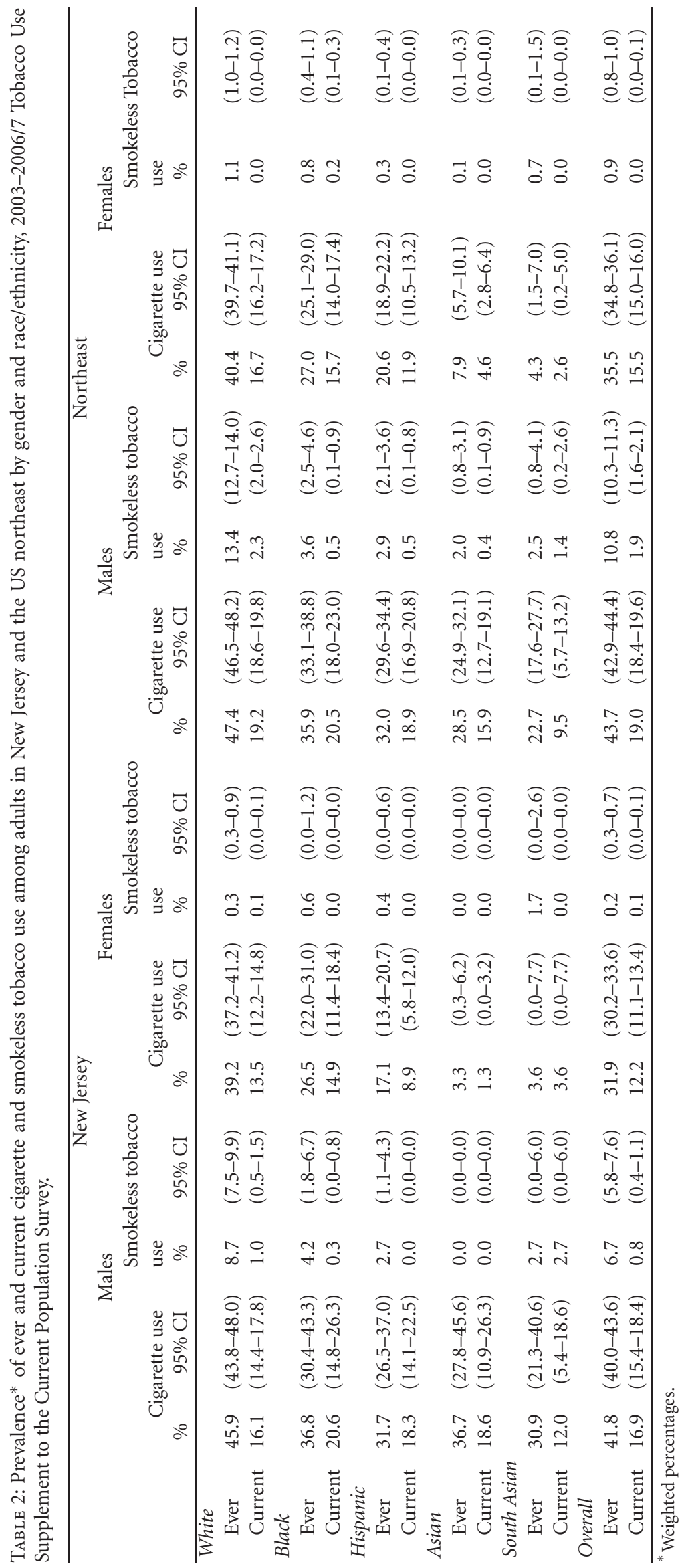


TABLE 3: Country of origin and immigration status among South Asian adults in the US northeast overall and among ever and current cigarette smokers and smokeless tobacco users by gender, 2003-2006/7 Tobacco Use Supplement to the Current Population Survey.

\begin{tabular}{|c|c|c|c|c|c|}
\hline & Overall & Ever smoker & Current smoker & Ever SLT & Current SLT \\
\hline \multicolumn{6}{|l|}{ Males } \\
\hline 1st gen American of South Asian descent & 8.4 & 10.6 & 6.0 & 1.3 & 0.0 \\
\hline India & 70.0 & 66.1 & 57.8 & 90.8 & 85.9 \\
\hline Pakistan & 9.6 & 10.7 & 23.4 & 7.9 & 14.1 \\
\hline Bangladesh & 12.0 & 12.5 & 12.9 & 0.0 & 0.0 \\
\hline \multicolumn{6}{|l|}{ Females } \\
\hline 1st gen American of South Asian descent & 17.6 & 46.6 & 50.0 & 31.2 & \multirow{4}{*}{ No current use } \\
\hline India & 65.6 & 43.9 & 34.4 & 68.8 & \\
\hline Pakistan & 11.1 & 9.5 & 15.5 & 0.0 & \\
\hline Bangladesh & 5.6 & 0.0 & 0.0 & 0.0 & \\
\hline
\end{tabular}

$[10,11]$, other studies have found high rates of smoking in certain subgroups of South Asians, particularly Bangladeshis $[12,13]$. Therefore, population level data collection measures that consider South Asians as a single group will likely miss important country of origin differences in tobacco use behavior, and possibly oral cancer rates. This has critical tobacco dependence treatment implications as effective treatments may vary based on the particular tobacco product.

This study has some limitations that bear mentioning. First, we limited our focus to the northeast. While one out of three South Asians reside in the northeast, the extent to which the findings reported here are generalizable to those residing elsewhere is a valid concern. However, we could find no published reports which provided details on the extent to which those in the northeast may differ from their other US counterparts. Second, the number of participants, especially females and those from particular countries of origin are limited. Therefore, conclusions based on these small numbers should be made with caution. However, a strength of this study was our ability to identify and disaggregate South Asians from Asians overall. Our initial analysis (not shown in this paper) indicated that had we analyzed Asians in aggregate, the rates of smokeless tobacco use would have been masked, yielding extremely low prevalence estimates. Third, tobacco control surveillance systems, which are populationbased, ask about traditional "Western" tobacco products, such as cigarettes and moist snuff. Subsequently, we suspect that the prevalence data presented here may underestimate tobacco use as indigenous tobacco products used by South Asians, such as bidi cigarettes, as well as gutka, zarda and paan masala, are not addressed on these surveys. Moreover, some of these indigenous smokeless tobacco products have high levels of tobacco-specific nitrosamines (TSNA) and are associated with substantial health risks that may be greater than their Western counterparts [32]. Lastly, methodological limitations in the TUS-CPS with regards to country of origin restrict our ability to further explore important within group variation for cigarette smoking and smokeless tobacco use among other South Asian immigrant populations (e.g., Sri Lanka, Nepal).

Despite these limitations, this study provides important population level data about differential tobacco use and emphasizes the need for further research that disaggregates
South Asian populations. Study findings also point to the need to develop, test, and disseminate multiple, targeted tobacco cessation and treatment interventions that take into account important sociocultural differences among South Asian populations as well as differences based on the particular tobacco product used. While only three empirical studies investigating smoking cessation interventions targeting the broader category of Asian Americans have been documented in the literature, the findings suggest that scientifically valid, culturally tailored, and language-specific interventions are effective in reducing tobacco usage among ethnically specific Asian American populations [33]. Lastly, the use of indigenous smokeless tobacco among South Asians deserves attention in the context of the current "harm reduction" debate, where some tobacco control professionals argue that smokers should switch to smokeless tobacco if they cannot quit. This debate is largely focused around "snus" a very low tobacco-specific nitrosamine (TSNA) product with notably lower health risks than cigarettes. The data available regarding indigenous South Asian SLT products are highly varied with the International Agency for Research on Cancer (IARC) finding higher levels of some TSNA (e.g., $\mathrm{NNK}$ ) in the smokeless products used in India relative to North American and European smokeless tobacco products $[24,25]$, and since levels of TSNA's are influenced by many factors (e.g., fermentation, processing, other nontobacco carcinogens such as areca nut), these products may be associated with substantially greater health risks than some Western products. For this reason, even though more data are needed describing the health risks and carcinogenic potential of South Asian SLT products that are available in the US, what is clear is that they are certainly not without harm and should not be marketed to the South Asian community as a safe alternative to smoking.

\section{Acknowledgments}

This research was supported through grants from the National Cancer Institute (P30 CA072720-13S8 and K01 CA131500). It was also supported by the Cancer Institute of New Jersey's Survey Research and Qualitative Methods Shared Resource. 


\section{References}

[1] U.S. Census Bureau, The Asian Population: 2000, Publication C2KBR/01-16, 2002, http://www.census.gov/prod/2002pubs/ c2kbr01-16.pdf.

[2] P. Joshi, S. Islam, P. Pais et al., "Risk factors for early myocardial infarction in South Asians compared with individuals in other countries," Journal of the American Medical Association, vol. 297, no. 3, pp. 286-294, 2007.

[3] T. A. Chowdhury, C. Grace, and P. G. Kopelman, "Preventing diabetes in South Asians," British Medical Journal, vol. 327, no. 7423, pp. 1059-1060, 2003.

[4] D. Parkin, S. Whelan, J. Ferlay, L. Teppo, and D. Thomas, Eds., Cancer Incidence in Five Continents, vol. 8, International Agency for Research on Cancer, Lyon, France, 2002.

[5] SAALT, "Demographic characteristics of south Asians in the United States," http://www.saalt.org/pages/Reports\%7B47 \%7DPublications.html.

[6] J. Ye, G. Rust, P. Baltrus, and E. Daniels, "Cardiovascular risk factors among Asian Americans: results from a National Health Survey," Annals of Epidemiology, vol. 19, no. 10, pp. 718-723, 2009.

[7] M. Rani, S. Bonu, P. Jha, S. N. Nguyen, and L. Jamjoum, "Tobacco use in India: prevalence and predictors of smoking and chewing in a national cross sectional household survey," Tob Control, vol. 12, no. 4, article e4, 2003.

[8] M. S. Flora, C. G. N. Mascie-Taylor, and M. Rahman, "Gender and locality differences in tobacco prevalence among adult Bangladeshis," Tobacco Control, vol. 18, no. 6, pp. 445-450, 2009.

[9] A. Y. Alam, A. Iqbal, K. B. Mohamud, R. E. Laporte, A. Ahmed, and S. Nishtar, "Investigating socio-economic-demographic determinants of tobacco use in Rawalpindi, Pakistan," BMC Public Health, vol. 8, article 50, 2008.

[10] R. Balarajan and P. Yuen, "British smoking and drinking habits: variations by country of birth," Journal of Public Health, vol. 8, no. 3, pp. 237-239, 1986.

[11] H. S. Kohli, "A comparison of smoking and drinking among Asian and white schoolchildren in Glasgow," Public Health, vol. 103, no. 6, pp. 433-439, 1989.

[12] J. Bush, M. White, J. Kai, J. Rankin, and R. Bhopal, "Understanding influences on smoking in Bangladeshi and Pakistani adults: community based, qualitative study," British Medical Journal, vol. 326, no. 7396, pp. 962-965, 2003.

[13] National Health Service, "The health of minority ethnic groups, 2004 Health Survey for England," http://www.ic.nhs. uk/statistics-and-data-collections/health-and-lifestyles -related-surveys/health-survey-for-england.

[14] R. Lew and S. P. Tanjasiri, "Slowing the epidemic of tobacco use among Asian Americans and Pacific Islanders," American Journal of Public Health, vol. 93, no. 5, pp. 764-768, 2003.

[15] S. L. Ivey, S. Patel, P. Kalra, K. Greenlund, S. Srinivasan, and D. Grewal, "Cardiovascular health among Asian Indians (CHAI): a community research project," Journal of Interprofessional Care, vol. 18, no. 4, pp. 391-402, 2004.

[16] B. A. Glenn, Z. Surani, N. Chawla, and R. Bastani, "Tobacco use among South Asians: results of a community-university collaborative study," Ethnicity and Health, vol. 14, no. 2, pp. 131-145, 2009.

[17] S. L. Ivey, K. M. Mehta, C. L. Wassel Fyr, and A. M. Kanaya, "Prevalence and correlates of cardiovascular risk factors in South Asians: population-based data from two California surveys," Ethnicity and Disease, vol. 16, no. 4, pp. 886-893, 2006.
[18] US Department of Commerce, Census Bureau, "National Cancer Institute and Centers for Disease Control and Prevention Co-sponsored tobacco use supplement to the current population survey (2006-07)," 2008, http://riskfactor.cancer .gov/studies/tus-cps/.

[19] G. A. Giovino, M. W. Schooley, B. P. Zhu et al., "Surveillance for selected tobacco-use behaviors-United States, 19001994," Morbidity and Mortality Weekly Report, vol. 43, no. 3, pp. 1-43, 1994.

[20] Research Triangle Institute, SUDAAN User's Manual, Release 8.0, Research Triangle Institute, Research Triangle Park, NC, USA, 2001.

[21] S. Choi, S. Rankin, A. Stewart, and R. Oka, "Effects of acculturation on smoking behavior in Asian Americans: a meta-analysis," Journal of Cardiovascular Nursing, vol. 23, no. 1, pp. 67-73, 2008.

[22] M. White, J. Bush, J. Kai, R. Bhopal, and J. Rankin, "Quitting smoking and experience of smoking cessation interventions among UK Bangladeshi and Pakistani adults: the views of community members and health professionals," Journal of Epidemiology and Community Health, vol. 60, no. 5, pp. 405$411,2006$.

[23] P. C. Gupta and C. S. Ray, "Smokeless tobacco and health in India and South Asia," Respirology, vol. 8, no. 4, pp. 419-431, 2003.

[24] International Agency for Research on Cancer, Betel-Quid and Areca-Nut Chewing and Some Areca-Nut-Derived Nitrosamines, vol. 85 of IARC Monographs on the Evaluation of Carcinogenic Risks to Humans, World Health Organization International Agency for Research on Cancer, Lyon, France, 2004.

[25] International Agency for Research on Cancer, Smokeless Tobacco and Some Tobacco-Specific N-Nitrosamines, vol. 89 of IARC Monographs on the Evaluation of Carcinogenic Risks to Humans, World Health Organization International Agency for Research on Cancer, Lyon, France, 2007.

[26] J. Ferlay, F. Bray, P. Pisani, and D. M. Parkin, "Globocan 2002: cancer incidence, mortality and prevalence worldwide, version $2.0, " 2002$.

[27] R. Sankaranarayanan, "Oral cancer in India: an epidemiologic and clinical review," Oral Surgery Oral Medicine and Oral Pathology, vol. 69, no. 3, pp. 325-330, 1990.

[28] A. Auluck, G. Hislop, C. Poh, L. Zhang, and M. P. Rosin, "Areca nut and betel quid chewing among South Asian immigrants to Western countries and its implications for oral cancer screening," Rural and Remote Health, vol. 9, no. 2, p. 1118, 2009.

[29] L. Liu, S. K. S. Kumar, P. P. Sedghizadeh, A. N. Jayakar, and C. F. Shuler, "Oral squamous cell carcinoma incidence by subsite among diverse racial and ethnic populations in California," Oral Surgery, Oral Medicine, Oral Pathology, Oral Radiology and Endodontology, vol. 105, no. 4, pp. 470-480, 2008.

[30] D. R. Moles, S. Fedele, P. M. Speight, S. R. Porter, and I. dos Santos Silva, "Oral and pharyngeal cancer in South Asians and non-South Asians in relation to socioeconomic deprivation in South East England," British Journal of Cancer, vol. 98, no. 3, pp. 633-635, 2008.

[31] H. Winter, K. K. Cheng, C. Cummins, R. Maric, P. Silcocks, and C. Varghese, "Cancer incidence in the south Asian population of England (1990-92)," British Journal of Cancer, vol. 79, no. 3-4, pp. 645-654, 1999.

[32] A. McNeill, R. Bedi, S. Islam, M. N. Alkhatib, and R. West, "Levels of toxins in oral tobacco products in the UK," Tobacco Control, vol. 15, no. 1, pp. 64-67, 2006. 
[33] M. S. Chen Jr. and H. Tang, "Review of smoking cessation research among Asian Americans: the state of the research," Nicotine and Tobacco Research, vol. 9, supplement 3, pp. 485493, 2007. 


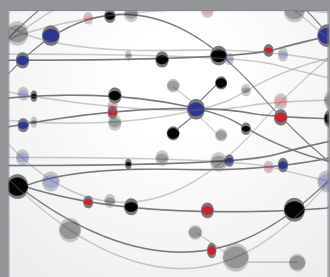

The Scientific World Journal
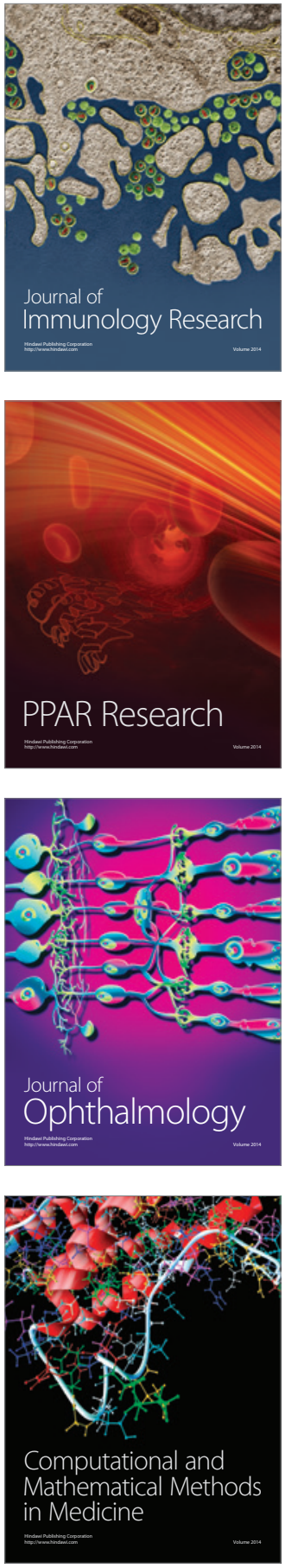

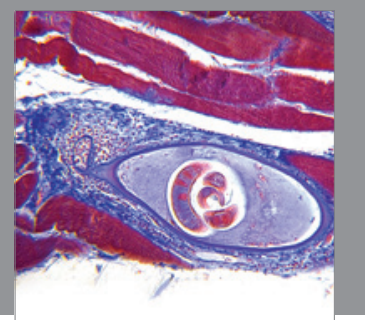

Gastroenterology

Research and Practice
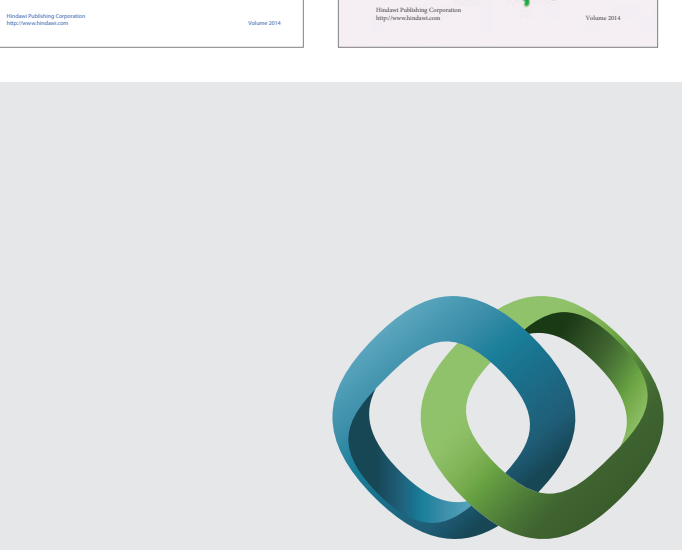

\section{Hindawi}

Submit your manuscripts at

http://www.hindawi.com
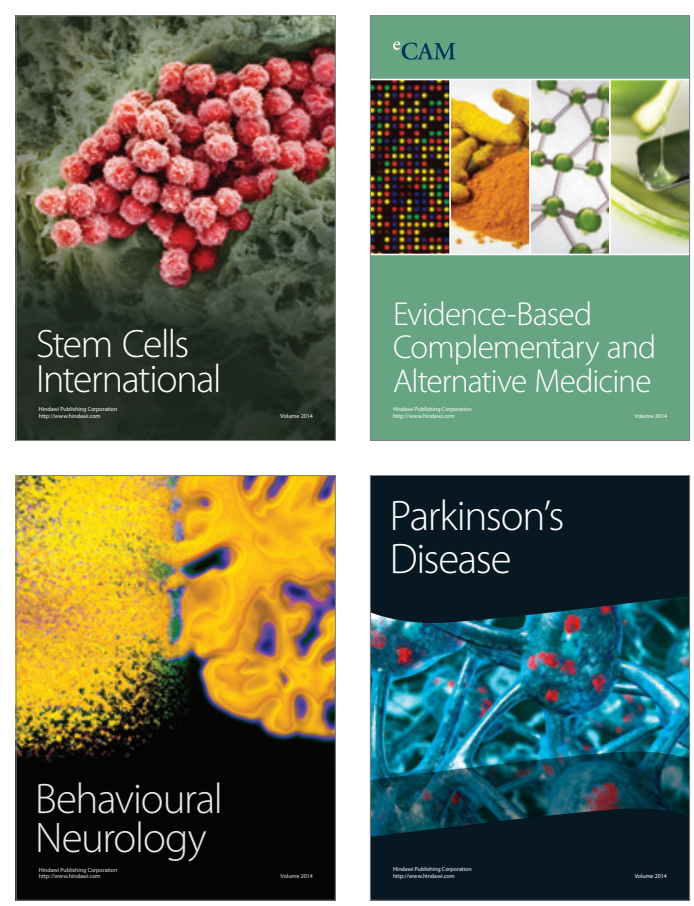

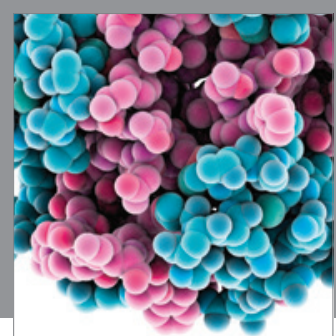

Journal of
Diabetes Research

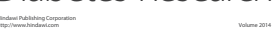

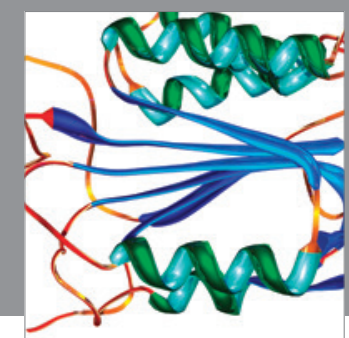

Disease Markers
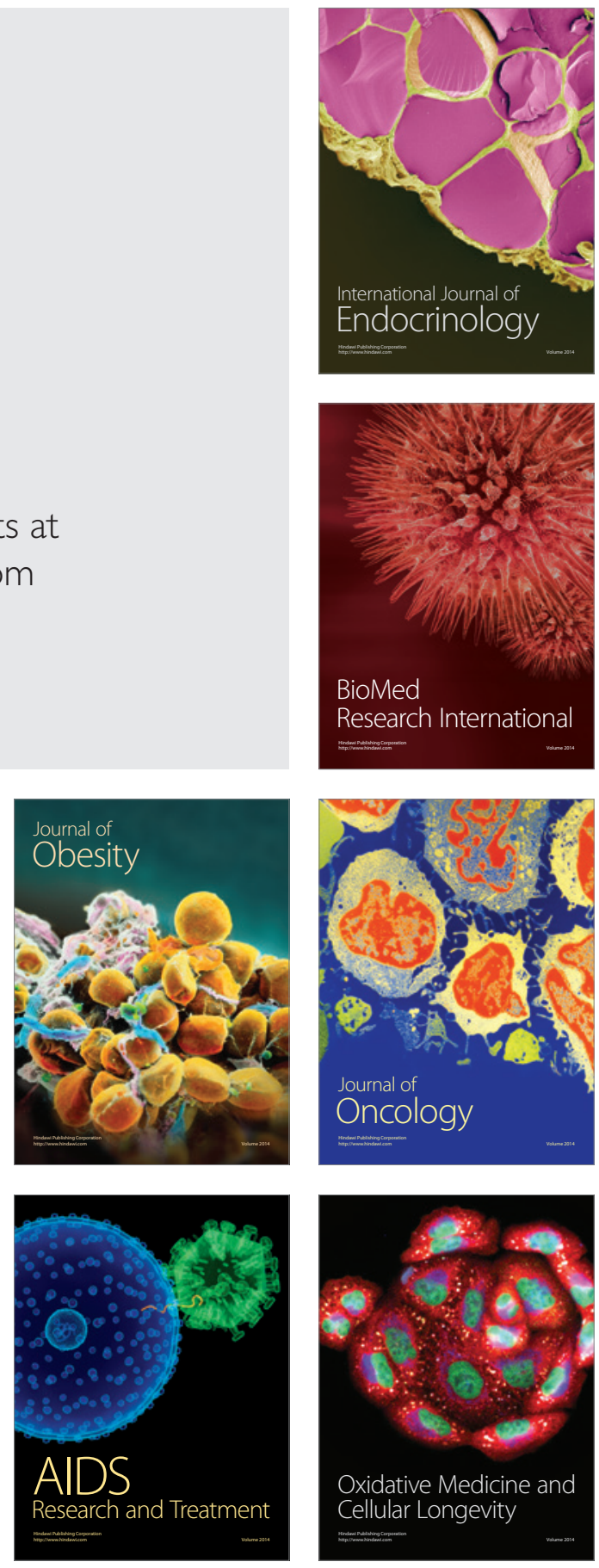